Copyright (C) 2021 by Cherkas Global University

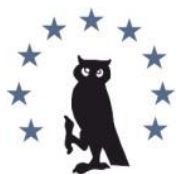

Published in the USA

Slavery: Theory and Practice

Has been issued since 2016.

E-ISSN: 2500-3755

2021. 6(1): 35-41

DOI: 10.13187/slave.2021.1.35

https://stp.cherkasgu.press

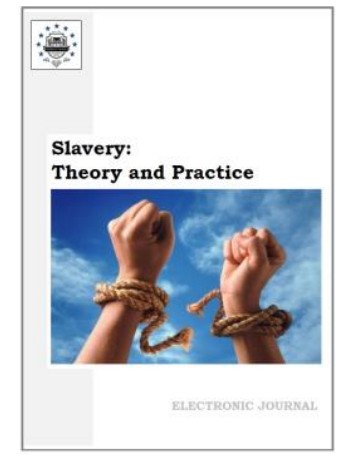

\title{
Slavery in the Ottoman Empire (the first half of the XIX century): on the Status of Monastic Slaves
}

\author{
Anatoliy V. Goncharenko a, * \\ ${ }^{a}$ Sumy State University, Sumy, Ukraine
}

\section{Abstract}

The article considers the monastery slaves on the example of the Ottoman Empire in the first half of the 19th century. The attention is paid to the spheres of use of slaves and their wages.

As sources in the work, materials of personal origin were used, namely, the memoirs of T. Lapinsky "The Highlanders of the Caucasus and their liberation struggle against the Russians", the memoirs of N.N. Muravyov-Karsky "Travel to Turkmenistan and Khiva in 1819 and 1820, the Guards General Staff of Captain Nikolai Muravyov, sent to these countries for negotiations". As a source, we also involved the work of Archimandrite Prokofy "Sinai monastery". The work used the historical-comparative method, thanks to which slavery in Egypt was considered in comparison with a similar phenomenon in Central Asia and the Caucasus.

In conclusion, the author states that the example of monastic slaves is a unique phenomenon on the territory of the Ottoman Empire in the first half of the 19th century. Despite the dominant role of Islam in the region, the Orthodox monastery (Sinai Monastery) after the collapse of Byzantium, thanks to economic opportunities, not only survived, but also gained influence on the local Bedouin tribes. The rights of the monastery to the monastery slaves were enshrined in the Ottoman firmans and this allowed the monastery to carry out agricultural activities. For work on agricultural land, the monks paid slaves significant funds, besided this, the slaves received the exclusive right to conduct study tours around the Sinai monastery, as well as food.

Keywords: Egypt, Ottoman Empire, slave trade, monastery slaves, slave markets.

\section{1. Введение}

Когда мы говорим о рабстве в Османской империи, то сразу пытаемся ассоциировать это явление с тремя основными категориями зависимых: мужчины-рабы, наложницы, а также рабы и евнухи, используемые в домашнем хозяйстве. Как известно, источников пополнения рабов было два: это военные действия (захват новых пленников) и рождение потомства у рабов. В данной статье речь пойдет о таком редко встречаемом понятии, как монастырские рабы.

\section{2. Материалы и методы}

В качестве источников в работе были использованы материалы личного происхождения, а именно воспоминания $\mathrm{T}$. Лапинского «Горцы Кавказа и их освободительная борьба против русских» (Лапинский, 1995) и воспоминания

\footnotetext{
${ }^{*}$ Corresponding author

E-mail addresses: a.goncharenko@yur.sumdu.edu.ua (A.V. Goncharenko)
} 
Н.Н. Муравьева-Карсского «Путешествие в Туркмению и Хиву в 1819 и 1820 годах, гвардейского Генерального Штаба капитана Николая Муравьева, посланного в сии страны для переговоров» (Муравьев-Карсский, 1822). В качестве источника нами привлечена также работа архимандрита Прокофия «Синайская обитель» (Порфирий, 1848).

В работе использованы традиционные принципы исторического исследования: историзма, системности и объективности. Помимо этого, нами был применен историкосравнительный метод, благодаря которому рабство в Египте было рассмотрено в сравнении с аналогичным явлением в Центральной Азии и на Кавказе.

\section{3. Обсуждение}

Историография по теме нашего исследования отличается своей малочисленностью. Среди трудов, рассматривающих одновременно и церковные вопросы, и вопросы рабства, можно назвать работу А.Р. Корсунского «Церковь и рабский вопрос в IV веке» (Корсунский, 2019).

Нужно понимать, что значительная часть рабов Османской империи была завезенной. Массово закупались рабы, например, из Черкесии. Так, в работе А.А. Черкасова (Cherkasov et al., 2017) делалась попытка рассмотреть «груз» и стоимость живого товара на работорговом судне, которое отправлялось в 1810 г. из Черкесии в Османскую империю. Теме работорговли в Черкесии уделили внимание И.А. Ермачков и др. (Ermachkov, 2020; Ermachkov, 2021), которые обратили внимание на некоторые региональные особенности этого явления.

В 2020 г. А.А. Черкасов опубликовал крупную коллекцию документов о рабстве на территории Черкесии - «Черкесские невольничьи повествования» (Cherkasov, 2020). В результате на основе этих документов Т.А. Магсумов и другие рассмотрели вопросы исхода ногайцев из территории Черкесии (Magsumov et al., 2021). Данная тема свидетельствует о том, что перспектива рабства сильно влияла на миграцию населения, желающего от него спастись. Тему рабовладения и работорговли у ногайцев затрагивала в своем исследовании и А.К. Аджиниязова (Аджиниязова, 2017). Исследователь А.Ю. Перетятько также обратился к теме «Черкесских невольничьих повествований», опубликовав работу «The Experience of Employing the Slave Narrative Genre in Describing the History of the Caucasus» (Peretyatko, 2021).

Если учесть, что невольничьи рынки Черкесии и Центральной Азии были связаны, то мы хотели бы упомянуть и несколько работ о рабстве и работорговле в Центральной Азии. Одной из них является исследование И.А. Ермачкова и других «The Slavery in Central Asia (the first half of the XIX century): the Nature and Manifestations» (Ermachkov, 2020). Эту же тему затронула в своем исследовании F. Tojieva, рассмотрев данное явление на примере Хивинского ханства (Tojieva, 2020). К теме рабства в Центральной Азии обращалась и Ю.А. Лысенко в работе «Slave Trade and Slavery in the Central Asian Outskirts of the Russian Empire (XVIII-XIX centuries)» (Lysenko, 2018). Понятия «раб» и «рабство» в традиционном казахском праве рассматривала М. Мурзакулова (Myrzakulova, 2015). Институт рабства в феодальном Дагестане и торговля «живым товаром» на Северном Кавказе в XVII - первой половине XIX вв. изучались Е.И. Иноземцевой (Иноземцева, 2014).

В последнее время проводились и историко-сравнительные исследования. Так, М. Шмигель и А.А. Черкасов предприняли попытку сравнения рабства в Черкесии и на территории Соединенных Штатов Америки (Smigel, Cherkasov, 2016).

\section{4. Результаты}

В 531 г. от рождества Христова на Синайском полуострове византийский император Юстиниан повелел построить Синайский монастырь (Порфирий, 1848: 171), с этого времени и начинается история этой обители. При строительстве были возведены не только здания, но и стены вокруг обители. Монастырь был построен в горах, у восточной части горы Хорива. В стенах были предусмотрены амбразуры для лучников. Главным храмом был храм Преображения Господня. Синайский монастырь имел важное значение в деле распространения христианства, и часто в обитель приходили христианские паломники из Палестины. За свою историю обитель разрушалась дважды: в первый раз в 1312 г. от землетрясения и в 1797 г. от ветхости. Вне всякого сомнения, в развалины обители водворились бы бедуины, если бы каждый раз не поспевала помощь жертвователей из разных уголков христианского мира. 
В первой половине XIX века Синайский монастырь (Рис. 1) продолжал свою работу по приюту паломников, благодаря пожертвованиям монастырь оказывал продовольственную помощь и местному бедуинскому населению.

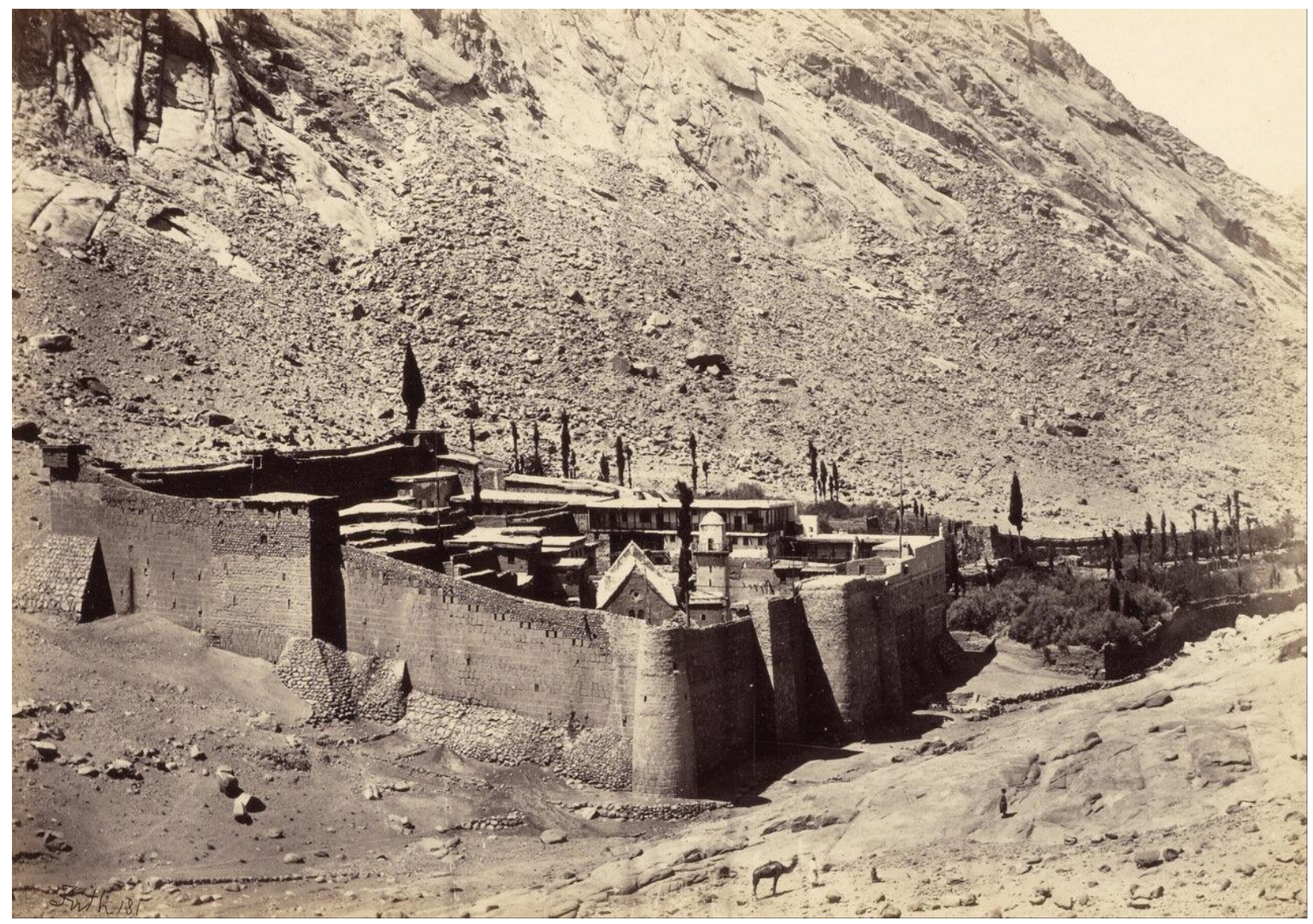

Рис. 1. Синайский монастырь (1860 г.)

Экономическое благополучие Синайского монастыря зиждилось на собственности монастыря, среди которой были имения и подворья. Вот лишь некоторые из них: на Синайском полуострове - рядом с монастырем большой сад с плодовыми деревьями, еще один сад между горой Хорива и Екатерининской горой и большие финиковые сады около селения Раифы. В Египте - в Каире монастырю принадлежали 27 домов с лавками, которые сдавались внаем (приобретены благодаря духовным завещаниям христиан). Собственность монастыря была в Индии, Сирии, Малой Азии, на островах Средиземного моря и в Европе, что позволило монастырю не только сохраниться, но и динамично развиваться.

Синайский монастырь был окружен разными арабскими племенами, некоторые из них являлись рабами монастыря, иные - защитниками, а остальные никак не были связаны с ним.

Монастырские рабы назывались джебелье, они были потомками влахов и египтян, которые были поселены около монастыря по приказу царя Юстиниана I и с течением времени приняли религию, обычаи и нравы синайских арабов. Лишь немногие из них долго оставались в христианской вере. Известно, что последняя христианка умерла в 1750 г. Монастырские рабы ничем не отличались от других туземцев Синайского полуострова. Численность их составляла до 375 семейств, или 1,5 тыс. человек, вместе с детьми и женщинами (Порфирий, 1848: 203).

Монастырские рабы были разделены следующим образом: тебны - работали в садах около Фарана, бегии - в финиковых садах Раифы, саттлы - в других садах. Два семейства работали в саду в долине эль-Леджа. Все эти семейства получали по 250 пиастров в год, а помимо этого, получали хлеб (Порфирий, 1848: 204). 
Шесть-семь рабов были постоянно задействованы на работах в монастыре, но их работа была сменной. Однако самая большая часть монастырских рабов в работе вообще не была задействована, а кочевала около монастыря в горах, проживала в палатках. Когда рабов призывали на помощь для каких-либо работ, тогда им давалась условная плата ячменем. Им же было предоставлено исключительное право водить паломников по священным окрестностям монастыря: за это они получали от монастыря плату ячменем и от паломников несколько пиастров (Порфирий, 1848: 204). Но они никогда не сопровождали паломников ни от Синая до Каира, ни обратно, так как для этого у них не было верблюдов. Данная обязанность по договору исполнялась другими арабами - защитниками монастыря.

Рабы снабжались одеждой на самое продолжительное время; а на каждые два дня они получали питание - черствые хлебцы, величиной менее ладони, испеченные из муки с примесью большей части отрубей. Пайка была следующей: мужчины получали по 5 хлебцев, женщины и юноши - по 3, девицы и дети - по 2 (Порфирий, 1848: 204-205). По примерным оценкам, на рабов в год тратилось монастырем до 50 тонн муки и отрубей. Эта группа монастырских рабов была самой бедной. Многие ее представители были полуголыми, свой рацион питания они дополняли травой и кореньями. Тем не менее они любили монастырь. Когда они видели дикея (настоятеля монастыря), то в знак уважения они целовали его правую ногу.

Важно отметить, что в первой половине XIX века отношение к рабам как на Кавказе, так и в Центральной Азии было в одинаковой мере бесчеловечным. Так, например, Т. Лапинский описывал, что среди пленников в Черкесии было большое количество самоубийц - «(Раб - Авт.) предмет недоверия, презрения и насмешек, едва прикрытый лохмотьями, большую часть года подвергающийся мучительнейшему голоду, продаваемый как скот, он имеет только один выход - покончить свое существование в этих негостеприимных для него горах» (Лапинский, 1995: 146).

Питание рабов в Центральной Азии и Египте было одинаково скудным. Так, Н.Н. Муравьев-Карсский вспоминал, что рацион рабов в Центральной Азии «состоял из хлебного пайка, который невольник получал от хозяина, но, продавая часть его для скопления денег на собственный выкуп и одежду, невольник часто целые дни проводил без пищи или кормился за счет подаяний или воровства» (Муравьев-Карсский, 1822: 128).

Многие вопросы взаимодействия монастыря и его рабов были прописаны: так, в случае нападения других арабов на монастырь 70 рабов были обязаны войти во внутрь и с оружием в руках защищать монастырь (Порфирий, 1848: 204). Однако этого никогда не случалось, так как и магометанское правительство Египта было заинтересовано в работе монастыря в сугубо экономическом аспекте (мало того, что монастырь платил налоги, так еще и давал работу и питание нескольким местным племенам).

Несколько слов скажем и кафирах - защитниках монастыря. Кафирами Синайского монастыря являлись три арабских племени: алейкаты, улад-саиды и аваримы. Алейкаты кочевали в долине Насб и водили свои стада в долины Вата, далеко на Запад от обители. Улад-саиды и аваримы кочевали со своими стадами в долинах Мукаттабской, Фаранской и в соседних с ними, на северо-западе от обители, но ближе к ней. Эти племена были древними племенами на Синайском полуострове. Кафиры, по договорам с Синайским монастырем, обязаны были защищать монастырь с оружием в руках в случае нападения других арабских племен, а также доставлять из Каира (столица Египта) на своих верблюдах за оговоренную плату продовольствие, товары и паломников. Поэтому монастырь отказывался от права держать своих вьючных животных. До 1838 г. кафиры по договору получали от монастыря за доставку каждого ардеба (примерно 9 пудов, или 144 кг) по 25 пиастров (примерно 5 руб. ассигнациями), а также хлеб с похлебкой после привоза вещей. Однако с 1839 г. монастырь стал платить за каждый ардеб по 40 пиастров (8 рублей), а пищи уже не давал (Порфирий, 1848: 206).

С лиц, отправляющихся на Синай и с Синая в Каир, кафиры брали по 150 пиастров за наем одного верблюда в одну сторону. Время никогда не бралось ими в расчет, поэтому паломник или путешественник мог ехать с ними более 10 дней. Однако бедуины всегда рассчитывали на денежный подарок, так называемый бакшиш.

Интересно, что русские паломники, по особому договору монастыря с кафирами, платили им за верблюда только 80 пиастров (Порфирий, 1848: 207). 
Регламентирована была и защита чести: так, если кафир или другой туземный араб обидит синайского монаха, то по суду главного шейха он должен был заплатить 25 пиастров, столько же должен был заплатить и монах, если он обидел араба (Порфирий, 1848: 207).

Право на монастырских рабов было прописано фирманами египетских шейхов. В 1831 г. главный синайский шейх Салех пытался подчинить своей власти монастырских рабов и свои требования начал предъявлять в ультимативной форме. Рабы, испугавшись, убежали на гору эль-Тих в 5 днях пути от монастыря на север. Тогда дикей (настоятель монастыря) явился к ним с одним старцем и стал их уговаривать вернуться назад в свои кочевья. Рабы согласились только при одном условии, что египетское начальство поручится в их безопасности и неподчинении никакой другой власти, кроме монастырской. Тогда дикей отправился в Суэц и начальнику города предъявил фирманы, в которых ясно был прописан статус монастырских рабов. Шейх Салех за доставленные неудобства был вынужден заплатить даже пеню (Порфирий, 1848: 208-209).

В 1845 г. дикей монастыря отец Никодим крестил двух монастырских рабов и никто из бедуинов не сообщил об этом египетскому начальству: такова была степень уважения монастырского дикея. Тем не менее более широко распространить христианство дикей также не мог, так как это повлекло бы межплеменные столкновения на религиозной почве и проблемы для монастыря от правительства

\section{5. Заключение}

В заключении мы хотели бы отметить, что пример монастырских рабов является уникальным явлением на территории Османской империи в первой половине XIX веке. Несмотря на доминирующую роль ислама в регионе, православная обитель (Синайский монастырь) после крушения Византии, благодаря экономическим возможностям, не только сохранилась, но и обрела влияние на местные бедуинские племена. Права монастыря на монастырских рабов были закреплены в османских фирманах, и это позволяло монастырю осуществлять сельскохозяйственную деятельность. За работу на сельскохозяйственных угодиях монахи платили рабам значительные средства, помимо этого, рабы получали исключительное право на проведение ознакомительных экскурсий по окрестностям Синайской обители, а также питание.

\section{Литература}

Иноземцева, 2014 - Иноземцева Е.И. Институт рабства в феодальном Дагестане. Очерки истории. Махачкала, 2014. 298 с.

Корсунский, 2019 - Корсунский A.P. Церковь и рабский вопрос в IV веке // Средние века. 2019. № 80(4). С. 32-59.

Лапинский, 1995 - Лапинский T. Горцы Кавказа и их освободительная борьба против русских. Нальчик, 1995. 464 с.

Муравьев-Карсский, 1822 - Муравъев-Карсский Н.Н. Путешествие в Туркмению и Хиву в 1819 и 1820 годах, гвардейского Генерального Штаба капитана Николая Муравьева, посланного в сии страны для переговоров. Москва, 1822.

Порфирий, 1848 - Порфирий Архим. Синайская обитель // Журнал министерства народного просвещения. 1848. № 6о. С. 171-210.

Cherkasov et al., 2017 - Cherkasov A.A., Ivantsov V.G., Smigel M., Molchanova V.S. The List of Captives from the Turkish Vessel Belifte as a Source of Information on the Slave Trade in the NorthWestern Caucasus in the early 19th century. // ANNALES. Ser. hist. sociol. 2017. 27(4): 854-864.

Cherkasov, 2020 - Cherkasov A.A. The Circassian Slave Narratives (A Documentary Collection) // Bylye Gody. 2020. 57-1(3-1): 1415-2266.

Ermachkov, 2020 - Ermachkov I.A., Koroleva L.A., Mineeva E.K., Balanyuk L.L. Slave Trade in Circassia (first half of the XIX century): Some Characteristic Features // Bylye Gody. 2020. 58(4): 2464-2470.

Ermachkov, 2021 - Ermachkov I.A., Koroleva L.A., Mineeva E.K., Balanyuk L.L. The Slavery in Central Asia (the first half of the XIX century): the Nature and Manifestations // Bylye Gody. 2021. 16(1): 110-117.

Lysenko, 2018 - Lysenko Y.A. Slave Trade and Slavery in the Central Asian Outskirts of the Russian Empire (XVIII-XIX centuries) // Bylye Gody. 2018. 47(1): 172-182. 
Magsumov et al., 2021 - Magsumov T.A., Zulfugarzade T.E., Korolev A.A., Krasnenkova E.V. The Nogai Exodus from Circassia (1793-1839) based on the materials of "The Circassian Slave Narratives" // Bylye Gody. 2021. 16(1): 97-109.

Myrzakulova, 2015 - Myrzakulova $M$. Concept and features of slave and slavery in the traditional Kazakh law // Austrian Journal of Humanities and Social Sciences. 2015. 3(4): 99-101.

Peretyatko, 2021 - Peretyatko A.Yu. The Experience of Employing the Slave Narrative Genre in Describing the History of the Caucasus. // Vestnik of Saint Petersburg University. History. 2021. 66(1): 302-313.

Smigel, Cherkasov, 2016 - Smigel M., Cherkasov A.A. The Slavery in Circassia and the United States (1850-1860-ies years): General and Special // Bylye Gody. 2016. 42(4): 1182-1197.

Tojieva, 2020 - Tojieva F. Slavery relations and its sources in Khiva khanate // Journal of Critical Reviews. 2020. 7(12): 211-214.

Аджиниязова, 2017 - Аджиниязова А.К. Рабовладение и работорговля у ногайцев в XVIII - середины XIX в. // Известия Волгоградского государственного педагогического университета. 2017. № 7(120). С. 175-179.

\section{References}

Adzhiniyazova, 2017 - Adzhiniyazova, A.K. (2017). Rabovladenie i rabotorgovlya u nogajcev v XVIII - serediny XIX v. [Slavery and the slave trade among the Nogais in the 18th - mid19th centuries]. Izvestiya Volgogradskogo gosudarstvennogo pedagogicheskogo universiteta. 7(120): 175-179. [in Russian]

Cherkasov et al., 2017 - Cherkasov, A.A., Ivantsov, V.G., Smigel, M., Molchanova, V.S. (2017). The List of Captives from the Turkish Vessel Belifte as a Source of Information on the Slave Trade in the North-Western Caucasus in the early 19th century. ANNALES. Ser. hist. sociol. 27(4): 854-864.

Cherkasov, 2020 - Cherkasov, A.A. (2020). The Circassian Slave Narratives (A Documentary Collection). Bylye Gody. 57-1(3-1): 1415-2266. [in Russian]

Ermachkov, 2020 - Ermachkov, I.A., Koroleva, L.A., Mineeva, E.K., Balanyuk, L.L. (2020). Slave Trade in Circassia (first half of the XIX century): Some Characteristic Features. Bylye Gody. 58(4): 2464-2470.

Ermachkov, 2021 - Ermachkov, I.A., Koroleva, L.A., Mineeva, E.K., Balanyuk, L.L. (2021). The Slavery in Central Asia (the first half of the XIX century): the Nature and Manifestations. Bylye Gody. 16(1): 110-117.

Inozemceva, 2014 - Inozemceva, E.I. (2014). Institut rabstva v feodal'nom Dagestane. Ocherki istorii [The institution of slavery in feudal Dagestan. Essays on history]. Mahachkala, 298 p. [in Russian]

Korsunskij, 2019 - Korsunskij, A.R. (2019). Cerkov' i rabskij vopros v IV veke [Church and the slave question in the 4th century]. Srednie veka. 80(4): 32-59. [in Russian]

Lapinskii, 1995 - Lapinskii, T. (1995). Gortsy Kavkaza i ikh osvoboditel'naya bor'ba protiv russkikh [The highlanders of the Caucasus and their struggle for freedom against the Russians]. Nal'chik, 464 p. [in Russian]

Lysenko, 2018 - Lysenko, Y.A. (2018). Slave Trade and Slavery in the Central Asian Outskirts of the Russian Empire (XVIII-XIX centuries). Bylye Gody. 47(1): 172-182.

Magsumov et al., 2021 - Magsumov, T.A., Zulfugarzade, T.E., Korolev, A.A., Krasnenkova, E.V. (2021). The Nogai Exodus from Circassia (1793-1839) based on the materials of "The Circassian Slave Narratives". Bylye Gody. 16(1): 97-109.

Murav'ev-Karsskii, 1822 - Murav'ev-Karsskii, N.N. (1822). Puteshestvie v Turkmeniyu i Khivu v 1819 i 1820 godakh, gvardeiskogo General'nogo Shtaba kapitana Nikolaya Murav'eva, poslannogo v sii strany dlya peregovorov [Travel to Turkmenistan and Khiva in 1819 and 1820, by the Guards General Staff of Captain Nikolay Muravyov, who was sent to these countries for negotiations]. Moskva. [in Russian]

Myrzakulova, 2015 - Myrzakulova, $M$. (2015). Concept and features of slave and slavery in the traditional Kazakh law. Austrian Journal of Humanities and Social Sciences. 3(4): 99-101.

Peretyatko, 2021 - Peretyatko, A.Yu. (2021). The Experience of Employing the Slave Narrative Genre in Describing the History of the Caucasus. Vestnik of Saint Petersburg University. History. 66(1): 302-313. 
Porfirij, 1848 - Porfirij Arhim (1848). Sinajskaya obitel' [Sinai monastery]. Zhurnal ministerstua narodnogo prosveshcheniya. 60:171-210. [in Russian]

Smigel, Cherkasov, 2016 - Smigel, M., Cherkasov, A.A. (2016). The Slavery in Circassia and the United States (1850-1860-ies years): General and Special. Bylye Gody. 42(4): 1182-1197.

Tojieva, 2020 - Tojieva, F. (2020). Slavery relations and its sources in Khiva khanate. Journal of Critical Reviews. 7(12): 211-214.

\title{
Рабство в Османской империи (первая половина XIX века): к вопросу о статусе монастырских рабов
}

\author{
Анатолий Владимирович Гончаренко ${ }^{\text {a ,* }}$ \\ а Сумский государственный университет, Сумы, Украина
}

Аннотация. В работе рассматривается жизнь монастырских рабов на примере Османской империи в первой половине XIX века. Уделено внимание сферам применения рабов и их оплаты труда.

В качестве источников в работе были использованы материалы личного происхождения, а именно воспоминания Т. Лапинского «Горцы Кавказа и их освободительная борьба против русских», воспоминания Н.Н. Муравьева-Карсского «Путешествие в Туркмению и Хиву в 1819 и 1820 годах, гвардейского Генерального Штаба капитана Николая Муравьева, посланного в сии страны для переговоров». В качестве источника нами привлечена также работа архимандрита Прокофия «Синайская обитель». В работе был применен историкосравнительный метод, благодаря которому рабство в Египте было рассмотрено в сравнении с аналогичным явлением в Центральной Азии и на Кавказе.

В заключении автор отмечает, что пример монастырских рабов является уникальным явлением на территории Османской империи в первой половине XIX веке. Несмотря на доминирующую роль ислама в регионе, православная обитель (Синайский монастырь) после крушения Византии, благодаря экономическим возможностям, не только сохранилась, но и обрела влияние на местные бедуинские племена. Права монастыря на монастырских рабов были закреплены в османских фирманах, и это позволяло монастырю осуществлять сельскохозяйственную деятельность. За работу на сельскохозяйственных угодиях монахи платили рабам значительные средства, помимо этого, рабы получали исключительное право на проведение ознакомительных экскурсий по окрестностям Синайской обители, а также питание.

Ключевые слова: Египет, Османская империя, работорговля, монастырские рабы, невольничьи рынки.

\footnotetext{
* Корреспондирующий автор

Адреса электронной почты: a.goncharenko@yur.sumdu.edu.ua (А.В. Гончаренко)
} 